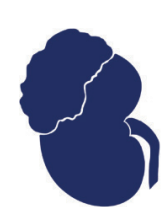

jkcvhl.com

ORIGINAL ARTICLE

\title{
Histologic Heterogeneity of Extirpated Renal Cell Carcinoma Specimens: Implications for Renal Mass Biopsy
}

\author{
Lauren M. Nahouraii ${ }^{1}$, Jordan L. Allen², Suzanne B. Merrill' ${ }^{2}$ Erik Lehman ${ }^{3}$, Matthew G. Kaag, ${ }^{2}$ \\ Jay D. Raman²
}

${ }^{1}$ College of Medicine, Pennsylvania State University, Hershey, PA, USA; ${ }^{2}$ Division of Urology, Department of Surgery, Penn State College of Medicine, Hershey, PA, USA; ${ }^{3}$ Department of Public Health Sciences, Penn State College of Medicine, Hershey, PA, USA

\begin{abstract}
Pathologic characteristics of extirpated renal cell carcinoma (RCC) specimens $<7 \mathrm{~cm}$ were reviewed to get better information on technical nuances of renal mass biopsy (RMB). Specimens were stratified according to tumor stage, nuclear grade, size, histology, presence of lymphovascular invasion (LVI), necrosis, and sarcomatoid features. When considering pT1 $(0-7 \mathrm{~cm})$ tumors, pT1b (4-7 cm) RCC masses were more likely to have necrosis $(43 \%$ vs $16 \%, \mathrm{P}<0.001)$, LVI $(6 \%$ vs $2 \%, \mathrm{P}=0.024)$, high-grade nuclear elements $(29 \%$ vs $17 \%$, P < 0.001$)$, and sarcomatoid features $(2 \%$ vs $0 \%, \mathrm{P}=0.006)$ compared with pT1a $(0-4 \mathrm{~cm})$ tumors. Additionally, pT3a tumors were more highly associated with necrosis $(\mathrm{P}=0.005)$, LVI, sarcomatoid features, and high-grade disease $(\mathrm{P}$ for all $<0.001)$ when compared to $\mathrm{pT} 1$ masses. For masses $\leq 4 \mathrm{~cm}, \mathrm{pT} 3 \mathrm{a}$ cancers were more likely to demonstrate necrosis ( $38 \%$ vs $16 \%$, P < 0.001$)$, LVI $(22 \%$ vs $2 \%$, P < 0.001$)$, high-grade nuclear elements $(45 \%$ vs $17 \%$, $\mathrm{P}<0.001)$, and sarcomatoid features $(12 \%$ vs $0 \%, \mathrm{P}<0.001)$ compared to pT1a tumors. Similarly, for masses $4-7 \mathrm{~cm}$, pathologic T3a tumors were significantly more likely to have sarcomatoid features $(12 \%$ vs $2 \%, \mathrm{P}=0.006)$ and LVI $(22 \% \mathrm{vs} 6 \%, \mathrm{P}=0.003)$ compared to pT1b tumors. In summary, pT3a tumors and those RCC masses $>4 \mathrm{~cm}$ exhibit considerable histologic heterogeneity and may harbor elements that are not easily appreciated with limited renal sampling. Therefore, if RMB is considered for renal masses greater than $4 \mathrm{~cm}$ or those that abut sinus fat, a multi-quadrant biopsy approach is necessary to ensure adequate sampling and characterization of the mass.
\end{abstract}

Keywords: heterogeneity; histology; renal cell carcinoma; renal mass biopsy; renal tumors

Received: April 26, 2020; Accepted after revision: July 29, 2020; Published: August 25, 2020

Author for Correspondence: Jay D. Raman, M.D., F.A.C.S., Division of Urology, Penn State Health Milton S. Hershey Medical Center, 500 University Drive, BMR Building c4830B, Hershey, PA 17033-0850, USA. Fax: 717-531-4475, Tel: 717-531-6979. Email: jraman@pennstate health.psu.edu

How to cite: Nahouraii LM et al. Histologic heterogeneity of extirpated renal cell carcinoma specimens: Implications for renal mass biopsy. J Kidney Cancer VHL. 2020;7(3): 20-25.

Doi: http://dx.doi.org/10.15586/jkcvhl.2020.134

Copyright: Nahouraii LM et al.

License: This open access article is licensed under Creative Commons Attribution 4.0 International (CC BY 4.0). http://creativecommons.org/ licenses/by/4.0

\section{Introduction}

Concerns regarding insufficient diagnostic yield coupled with false positive and negative rates contributed to the initial low utilization of renal mass biopsy (RMB) as a diagnostic tool for cortical masses over a decade ago. However, the rise of small renal masses discovered incidentally on imaging and advancements in systemic agents against particular renal cell carcinoma (RCC) subtypes have led to a resurgence of 
interest in incorporating $\mathrm{RMB}$ into the diagnostic algorithm of renal tumors (1). Furthermore, there has been growing interest in the use of genetic and molecular assessments that can potentially improve our ability to determine renal tumor biology and clinical behavior through RMB (2). Additionally, the increased adoption for active surveillance across a spectrum of RCC masses renewed optimism in the value of RMB information (3).

Current American Urological Association (AUA) clinical principles state that RMB should be considered when a mass is suspected to be hematologic, metastatic, inflammatory, or infectious. In the setting of a solid renal mass, AUA expert opinion does not recommend RMB for young or healthy patients who are willing to accept uncertainties associated with RMB, or for older or frail patients who will be managed conservatively regardless (4). Conversely, the European Urological Association practice guidelines recommend the use of $\mathrm{RMB}$ in patients who are candidates for active surveillance of small masses, to obtain histology before ablative treatments, and to select the most suitable medical and surgical treatment strategy in the setting of metastatic disease (level 3 evidence) (5).

The ideal RMB would not only differentiate between benign and malignant tumors, but importantly characterize key histologic features of RCC tumors to better guide the use of conservative versus interventional strategies. $\mathrm{RMB}$ is overall a safe procedure with core biopsy having superior accuracy compared to final needle aspiration (FNA) (6). There is some variability, however, in diagnostic accuracy particularly with respect to the impact of intratumoral heterogeneity on the interpretation of pathologic outcomes (6). Therefore, we evaluated the incidence of histologic heterogeneity, necrosis, lymphovascular invasion (LVI), and sarcomatoid features, in extirpated RCC specimens to better guide specific nuances of the $\mathrm{RMB}$ technique to optimize interpretation and accuracy.

\section{Patients and Methods}

After institutional review board (IRB) approval, the records of patients who underwent surgical resection of renal masses at a single academic institution between January 2000 and August 2017 were reviewed. Patients having incomplete data and benign masses were excluded. Masses $>7 \mathrm{~cm}$ were excluded due to the likelihood of extirpation versus diagnostic biopsy in general clinical practice. The baseline demographic, disease, and treatment-related parameters were extracted from the records in a de-identified manner. These data included age, gender, race, body mass index (BMI), American Society of Anesthesiologists (ASA) score, Eastern Cooperative Oncology Group (ECOG) performance status, and type of surgery (radical versus partial nephrectomy).

Final pathology reports of RCC specimens were used to stratify the masses according to size $(0-4 \mathrm{~cm}$ and $4-7 \mathrm{~cm})$ and pathologic stage (pT1a, pT1b, and pT3a). Within these groups, the annotation was made regarding histologic elements including nuclear grade and presence of LVI, necrosis, and sarcomatoid features (7). Low- and high-grade nuclear elements were defined as Fuhrman grades 1-2 and 3-4, respectively.

The data were analyzed using $\mathrm{R}$ software, version 9. The categorical variables were compared using Chi square test with Bonferroni correction to determine significance at a level of $\mathrm{P}<0.05$.

\section{Results}

A total of $659 \mathrm{RCC}$ specimens met the inclusion criteria. The pathologic characteristics of our cohort are included in Table 1. In summary, the mean tumor size was $3.5 \mathrm{~cm}$ (range, $0.9-7.0 \mathrm{~cm})$. Pathologic distribution of tumors included 404 (61\%) pT1a, 169 (26\%) pT1b, and 86 (13\%) pT3a. Histologic subtypes were distributed as 74\% clear cell, 19\% papillary, $6 \%$ chromophobe, and $1 \%$ other. Specimen stratification revealed $66 \%$ of tumors $0-4 \mathrm{~cm}$ and $34 \%$ of tumors $4-7 \mathrm{~cm}$ with no statistical difference in histologic subtype distribution across renal tumor sizes. Low and high nuclear grades were recorded in $486(74 \%)$ and $156(24 \%)$ cases, respectively. Necrosis, LVI, and sarcomatoid features occurred in 26, 6 , and $2 \%$ of cases, respectively.

Table 1: Pathologic characteristics of 659 RCC tumors $\leq$ $7 \mathrm{~cm}$ in size

\begin{tabular}{|l|c|}
\hline Pathologic Variable & No. (\%) \\
\hline $\begin{array}{l}\text { Histologic Subtype } \\
\text { Clear Cell }\end{array}$ & $487(74)$ \\
Papillary & $128(19)$ \\
Chromophobe & $38(6)$ \\
\hline Tumor Size (cm) & \\
$0-4$ & $433(66)$ \\
$4-7$ & $226(34)$ \\
\hline $\begin{array}{l}\text { Tumor Stage } \\
\text { pT1a } \\
\text { pT1b } \\
\text { pT3a }\end{array}$ & $404(61)$ \\
\hline Nuclear Grade & $169(26)$ \\
\hline Low & $86(13)$ \\
\hline High & $486(76)$ \\
\hline Necrosis & $156(24)$ \\
\hline Lymphovascular Invasion & $171(26)$ \\
\hline Sarcomatoid features & $38(6)$ \\
\hline
\end{tabular}


When considering pathologic T1 tumors, pT1b lesions (4-7 cm in size) were more likely to have necrosis (43\% vs $16 \%, \mathrm{P}<0.001)$, LVI ( $6 \%$ vs $2 \%, \mathrm{P}=0.024)$, high-grade nuclear elements $(29 \%$ vs $17 \%, \mathrm{P}<0.001)$, and sarcomatoid features $(2 \%$ vs $0 \%, \mathrm{P}=0.006)$ when compared to pT1a tumors ( $0-4 \mathrm{~cm}$ in size) (Table 2$)$.

Pathologic pT3a tumors were more highly associated with necrosis $(\mathrm{P}=0.005)$, LVI, sarcomatoid features, and high-grade disease $(\mathrm{P}$ for all $<0.001)$ when compared to $\mathrm{pT} 1$ masses (Table 3). Specifically, in masses $<4 \mathrm{~cm}$, pT3a cancers were more likely to demonstrate necrosis (38\% vs $16 \%$, $\mathrm{P}<0.001)$, LVI (22\% vs $2 \%, \mathrm{P}<0.001)$, high-grade nuclear elements $(45 \%$ vs $17 \%, \mathrm{P}<0.001)$, and sarcomatoid features $(12 \%$ vs $0 \%, \mathrm{P}<0.001)$ compared to pT1a tumors. For masses $4-7 \mathrm{~cm}$, pathologic pT3a tumors were significantly more likely to have sarcomatoid features (12\% vs $2 \%, \mathrm{P}=$ $0.006)$ and LVI $(22 \%$ vs $6 \%, \mathrm{P}<0.001)$ compared to $\mathrm{pT} 1 \mathrm{~b}$ tumors (Table 4).

\section{Discussion}

Renal mass biopsy is a tool increasingly available for accurate characterization of renal pathology prior to definitive intervention. While histologic heterogeneity of RCC is recognized, a quantitative assessment is more limited. Here, we investigated the pathologic characteristics of 659 extirpated RCC specimens to better characterize various elements that may impact the disease biology. In this regard, we observed

Table 2: Pathologic characteristics of 573 pT1 tumors stratified by size $(0-4 \mathrm{~cm}$ vs. $4-7 \mathrm{~cm})$

\begin{tabular}{|c|c|c|c|}
\hline Pathologic Variable & $\begin{array}{c}\text { pT1a }(n=404) \\
\text { No. }(\%)\end{array}$ & $\begin{array}{c}\text { PT1b }(n=169) \\
\text { No. }(\%)\end{array}$ & $P$ value \\
\hline $\begin{array}{l}\text { Histologic Subtype } \\
\text { Clear Cell } \\
\text { Papillary } \\
\text { Chromophobe }\end{array}$ & $\begin{array}{c}297(74) \\
81(19) \\
26(6)\end{array}$ & $\begin{array}{c}127(75) \\
33(20) \\
6(4)\end{array}$ & $\begin{array}{l}1.0 \\
1.0 \\
1.0\end{array}$ \\
\hline $\begin{array}{l}\text { Nuclear Grade } \\
\text { Low } \\
\text { High }\end{array}$ & $\begin{array}{r}326(81) \\
68(17)\end{array}$ & $\begin{array}{r}114(67) \\
49(29)\end{array}$ & $<0.001$ \\
\hline Necrosis & $66(16)$ & $72(43)$ & $<0.001$ \\
\hline LVI & $9(2)$ & $10(6)$ & 0.024 \\
\hline Sarcomatoid features & $0(0)$ & $4(2)$ & 0.006 \\
\hline
\end{tabular}

Table 3: Pathologic characteristics of $659 \mathrm{RCC}$ tumors $<7 \mathrm{~cm}$ in size stratified by stage (pT1 vs. pT3a)

\begin{tabular}{|c|c|c|c|}
\hline Pathologic Variable & $\begin{array}{c}\text { pT1 }(n=573) \\
\text { No. }(\%)\end{array}$ & $\begin{array}{c}\text { PT3a }(n=86) \\
\text { No. }(\%)\end{array}$ & $P$ value \\
\hline $\begin{array}{l}\text { Histologic Subtype } \\
\text { Clear Cell } \\
\text { Papillary } \\
\text { Chromophobe }\end{array}$ & $\begin{array}{c}424(74) \\
114(20) \\
32(6)\end{array}$ & $\begin{array}{c}63(73) \\
14(16) \\
6(7)\end{array}$ & $\begin{array}{l}1.0 \\
1.0 \\
1.0\end{array}$ \\
\hline $\begin{array}{l}\text { Nuclear Grade } \\
\text { Low } \\
\text { High }\end{array}$ & $\begin{array}{l}440(77) \\
117(20)\end{array}$ & $\begin{array}{l}46(53) \\
39(45)\end{array}$ & $<0.001$ \\
\hline Necrosis & $138(24)$ & $33(38)$ & 0.005 \\
\hline LVI & $19(3)$ & $19(22)$ & $<0.001$ \\
\hline Sarcomatoid features & $4(1)$ & $10(12)$ & $<0.001$ \\
\hline
\end{tabular}


Table 4: Pathologic characteristics of 659 RCC tumors $\leq 7 \mathrm{~cm}$ in size stratified by stage (pT1 vs. pT1b vs. pT3a)

\begin{tabular}{|c|c|c|c|c|}
\hline Pathologic Variable & $\begin{array}{c}\text { pT1a }(n=573) \\
\text { No. }(\%)\end{array}$ & $\begin{array}{c}\text { pT1b }(n=169) \\
\text { No. }(\%)\end{array}$ & $\begin{array}{c}\text { PT3a }(n=86) \\
\text { No. }(\%)\end{array}$ & $P$ value \\
\hline $\begin{array}{l}\text { Histologic Subtype } \\
\text { Clear Cell } \\
\text { Papillary } \\
\text { Chromophobe }\end{array}$ & $\begin{array}{c}297(74) \\
81(19) \\
26(6)\end{array}$ & $\begin{array}{c}127(75) \\
33(20) \\
6(4)\end{array}$ & $\begin{array}{c}63(73) \\
14(16) \\
6(7)\end{array}$ & $\begin{array}{l}0.94 \\
0.72 \\
0.35\end{array}$ \\
\hline $\begin{array}{l}\text { Nuclear Grade } \\
\text { Low } \\
\text { High }\end{array}$ & $\begin{array}{r}326(81) \\
68(17)\end{array}$ & $\begin{array}{r}114(67) \\
49(29)\end{array}$ & $\begin{array}{l}46(53) \\
39(45)\end{array}$ & $<0.001$ \\
\hline Necrosis & $66(16)$ & $72(43)$ & $33(38)$ & $<0.001$ \\
\hline LVI & $9(2)$ & $10(6)$ & $19(22)$ & $<0.001$ \\
\hline Sarcomatoid features & $0(0)$ & $4(2)$ & $10(12)$ & $<0.001$ \\
\hline
\end{tabular}

RCC masses $>4 \mathrm{~cm}$ and pT3a lesions, irrespective of size, were more likely to harbor areas of necrosis, LVI, high-grade nuclear elements, and sarcomatoid features.

Several other investigators have similarly investigated histologic characteristics of kidney cancers. Bedke et al. (8) demonstrated LVI in $5.5 \%$ of subjects with RCC and showed an association with advanced TNM (tumor, lymph node, metastasis) stages, high Fuhrman grade, and sarcomatoid features. LVI was the strongest factor associated with metastatic spread in all patients and also in a subgroup of patients with clear cell RCC. Pichler et al. (9) reported that sarcomatoid features, a highly aggressive form of RCC, were present in $5-8 \%$ of clear-cell RCC, $8-9 \%$ of chromophobe RCC, and $2-3 \%$ of papillary RCC. Additionally, about $75 \%$ of patients with sarcomatoid RCC presented with metastatic disease. Khor and colleagues (10) noted that tumor necrosis was present in $21 \%$ of cases of resected renal masses. After adjusting for age, tumor stage, and tumor size, necrosis was a significant predictor of overall survival on the multivariable analysis.

Nuclear grade heterogeneity is known to occur in small renal masses. In particular, Ball and colleagues (7) observed Fuhrman grade heterogeneity in $81.3 \%$ of all RCC tumors and $93.8 \%$ of high-grade specimens. Additionally, they investigated discordance within RCC specimens, defined as the highest grade is present in less than $50 \%$ of the specimen. They found discordance among $31.3 \%$ of all RCC tumors and $25 \%$ of high-grade specimens. A small-scale study confirmed that there is a statistically significant difference in the proportion of high-grade cases when compared with conventional $(36 \%)$ and total $(60 \%)$ samplings (11).

Qualitative data comparing histologic heterogeneity based on size and stage were limited in our literature review. Zhang et al. (12) showed a significant correlation between tumor size with grade and stage of lesions. Specifically, larger tumors were prone to have a higher grade and stage, and the probability of being clear cell subtype grew higher as the tumor size increased. In a recent study of a multi-quadrant biopsy technique for large renal masses (T2 or greater), $25.0 \%$ revealed multiple grades of tumors present among the cores, including $14.1 \%$ that contained high- and low-grade tumors. Of the 13 patients with sarcomatoid features identified from multi-quadrant biopsies, only $30.8 \%$ had sarcomatoid features present in every core sampled (13).

Heterogeneity is well established in RCC at the chromosomal and genomic sequence level. Moch et al. demonstrated variable intratumor loss of Von Hippel-Lindau (VHL) and chromosome 3 polysomy by fluorescence in situ hybridization in 53 patients with pT2 or greater RCC. However, the cytogenetic variability seen in these cases did not correlate with grade or stage $(2,14)$. Likewise, using multiregional exome sequencing, Gerlinger et al. (15) demonstrated intratumor heterogeneity in somatic mutations and genomic copy number across multiple regions in primary tumors and metastatic lesions in patients with clear cell RCC. Further research continues to identify genetic mutations with a recent meta-analysis tallying more than 19 (16).

Given the intratumoral heterogeneity demonstrated in this study, the probability of identifying all pathological features increases with each area tested by reducing sampling error. Hobbs et al. (17) demonstrated in an ex vivo study that obtaining multiple renal mass biopsy cores, compared with a single core biopsy, considerably improved diagnostic yield for histologic subtyping, accuracy, and cancer identification. Second peripheral and second central cores both increased cancer identification versus a single peripheral core (56-77\% and $80 \%$, respectively). They found no difference in cancer identification based on the location of a single core (central 
vs peripheral). These findings were reinforced by Abel et al. (13) in a prospective, in vivo study of multi-quadrant biopsies of large renal masses (T2 or greater). The use of at least four versus three or fewer biopsies from separate, solid enhancing areas of tumor decreased nondiagnostic rate (11 to $0 \%$ ) and improved sensitivity for detecting sarcomatoid features (25 to $87 \%$ ) without increasing the rate of complications. Multicenter studies are needed to confirm these findings.

There are limitations to this study. It is retrospective in nature and examines prior pathology reports. As such, we only have reports of the highest Fuhrman grade of an entire extirpated mass. Additionally, our institution currently follows the International Society of Urological Pathology 2018 guidelines requiring one section for each centimeter of the largest diameter of the tumor, with special attention to the areas with different macroscopic aspects including necrosis, but no precise guidelines for the distribution of sampling. The problem is that many RCC that appear homogeneous to the naked eye are heterogeneous under the microscope. Necrosis and sarcomatoid transformation can be discovered sometimes on a meticulous and skilled analysis by the naked eye, but tumor grade and eosinophilic cell change cannot (18). This point makes current routine tumor sampling an inconsistent sampling method $(19,20)$.

Furthermore, there are no standard recommendations on how renal carcinomas should be graded in needle-core biopsies. At our institution, we assign the highest grade to total specimen, but a system similar to Gleason scoring could prove more useful for stage stratification and treatment decisions. Further research is necessary to incorporate RMB into a standard diagnostic protocol for patients with renal cortical tumors.

\section{Conclusion}

Renal cell carcinoma masses $>4 \mathrm{~cm}$ and pT3a tumors (irrespective of size) exhibit considerable histologic heterogeneity and may harbor elements that are not easily appreciated with limited renal sampling. Therefore, if by cross-sectional radiography, renal masses appearing larger than $4 \mathrm{~cm}$ or those abutting sinus fat, a single percutaneous biopsy sample is likely not adequate. A multi-quadrant biopsy is necessary for these tumors to ensure accurate capture of histologic elements that may better reflect the differing underlying biology of these tumors. The minimum number and specific location of biopsies require continued investigation.

\section{Acknowledgments}

The authors are grateful to Ken and Bonnie Shockey Fund for Urologic Cancer Research at Penn State Health for their support in conducting this research.

\section{Conflict of interest}

The authors declare no potential conflicts of interest with respect to research, authorship, and/or publication of this article.

\section{References}

1. von Rundstedt FC, Mata DA, Kryvenko ON, Roth S, Degener S, Dreger NM, et al. Diagnostic accuracy of renal mass biopsy: An ex vivo study of 100 nephrectomy specimens. Int J Surg Pathol. 2016;24(3):213-18. https://doi.org/10.1177/1066896915625178

2. Höfflin R, Roth W, Sültmann H, Grüllich C, Hatiboglu G, Nyarangi-Dix J, et al. [Intratumoral heterogeneity in renal cell carcinoma. Molecular basis and translational implications]. Urologe A. 2015;54(6):800-3. https://doi.org/10.1007/ s00120-015-3800-9

3. Gordetsky J, Eich ML, Garapati M, Del Carmen Rodriguez Pena M, Rais-Bahrami S. Active surveillance of small renal masses. Urology. 2019;123:157-66. https://doi.org/10.1016/j. urology.2018.09.017

4. Campbell S, Uzzo RG, Allaf ME, Bass EB, Cadeddu JA, Chang A, et al. Renal mass and localized renal cancer: AUA guideline. J Urol. 2017;198(3):520-9. https://doi.org/10.1016/j. juro.2017.04.100

5. Ljungberg B, Bensalah K, Canfield S, Dabestani S, Hofmann F, Hora M, et al. EAU guidelines on renal cell carcinoma. Eur Urol. 2019;67(5):913-24. https://doi.org/10.1016/j.eururo.2015.01.005

6. Marconi L, Dabestani S, Lam TB, Hofmann F, Stewart F, Norrie J, et al. Systematic review and meta-analysis of diagnostic accuracy of percutaneous renal tumour biopsy. Eur Urol. 2016;69(4):660-73. https://doi.org/10.1016/j.eururo.2015.07.072

7. Ball MW, Bezerra SM, Gorin MA, Cowan M, Pavlovich CP, Pierorazio PM, et al. Grade heterogeneity in small renal masses: Potential implications for renal mass biopsy. J Urol. 2015;193(1):36-40. https://doi.org/10.1016/j.juro.2014.06.067

8. Bedke J, Heide J, Ribback S, Rausch S, de Martino M, Scharpf M, et al. Microvascular and lymphovascular tumour invasion are associated with poor prognosis and metastatic spread in renal cell carcinoma: A validation study in clinical practice. BJU Int. 2018;121(1):84-92. https://doi.org/10.1111/bju.13984

9. Pichler R, Compérat E, Klatte T, Pichler M, Loidl W, Lusuardi L, et al. Renal cell carcinoma with sarcomatoid features: Finally new therapeutic hope? Cancers (Basel). 2019;11(3):422. https://doi.org/10.3390/cancers11030422

10. Khor LY, Dhakal HP, Jia X, Reynolds JP, McKenney JK, Rini BI, et al. Tumor necrosis adds prognostically significant information to grade in clear cell renal cell carcinoma: A study of 842 consecutive cases from a single institution. Am J Surg Pathol. 2016;40(9):1224-31. https://doi.org/10.1097/ PAS.0000000000000690

11. López JI, Angulo JC. Pathological bases and clinical impact of intratumor heterogeneity in clear cell renal cell carcinoma. Curr Urol Rep. 2018;19(1):3. https://doi.org/10.1007/ s11934-018-0754-7

12. Zhang C, Li X, Hao H, Yu W, He Z, Zhou L. The correlation between size of renal cell carcinoma and its histopathological characteristics: A single center study of 1867 renal cell carcinoma cases. BJU Int. 2012;110(11 Pt B):E481-5. https://doi. org/10.1111/j.1464-410X.2012.11173.x 
13. Abel EJ, Heckman JE, Hinshaw L, Best S, Lubner $M$, Jarrard DF, et al. Multi-quadrant biopsy technique improves diagnostic ability in large heterogeneous renal masses. J Urol. 2015;194(4):886-91. https://doi.org/10.1016/j.juro.2015.03.106

14. Moch H, Schraml P, Bubendorf L, Richter J, Gasser TC, Mihatsch MJ, et al. Intratumoral heterogeneity of von HippelLindau gene deletions in renal cell carcinoma detected by fluorescence in situ hybridization. Cancer Res. 1998;58(11):2304-9.

15. Gerlinger M, Rowan AJ, Horswell S, Math M, Larkin J, Endesfelder D, et al. Intratumor heterogeneity and branched evolution revealed by multiregion sequencing. $\mathrm{N}$ Engl $\mathrm{J}$ Med. 2012;366(10):883-92. https://doi.org/10.1056/NEJMoa1113205

16. Beksac AT, Paulucci DJ, Blum KA, Yadav SS, Sfakianos JP, Badani KK. Heterogeneity in renal cell carcinoma. Urol Oncol. 2017;35(8):507-15. https://doi.org/10.1016/j.urolonc. 2017.05.006

17. Hobbs DJ, Zhou M, Campbell SC, Aydin H, Weight CJ, Lane BR. The impact of location and number of cores on the diagnostic accuracy of renal mass biopsy: An ex vivo study World J Urol. 2013;31(5):1159-64. https://doi.org/10.1007/ s00345-012-0868-3

18. Beaugerie A, Audenet F, Verkarre V, Delavaud C, Le Guilchet T, Hurel S, et al. Pathological heterogeneity in sporadic synchronous renal tumors: Is the histological concordance predictable? Urol Oncol. 2018;36(1):11.e17-11.e12. https://doi.org/10.1016/j. urolonc. 2017.09.002

19. Warren AY, Harrison D. WHO/ISUP classification, grading and pathological staging of renal cell carcinoma: Standards and controversies. World J Urol. 2018;36(12):1913-26. https://doi. org/10.1007/s00345-018-2447-8

20. Delahunt B, Cheville JC, Martignoni G, Humphrey PA, Magi-Galluzzi C, McKenney $\mathrm{J}$, et al. The International Society of Urological Pathology (ISUP) grading system for renal cell carcinoma and other prognostic parameters. Am J Surg Pathol. 2013;37(10):1490-504. https://doi.org/10.1097/ PAS.0b013e318299f0fb 